ESPAÇO TEMÁTICO: ESTADO, AUTORITARISMO E LUTA DE CLASSES

\title{
A moderna construção da vigilância e do controle social no Brasil
}

\author{
Vânia Morales Sierra ${ }^{1}$ \\ https://orcid.org/0000-0002-3778-6954
}

\author{
Silene de Moraes Freire ${ }^{2}$ \\ https://orcid.org/0000-0002-3824-7805
}

${ }^{1}$ Universidade do Estado do Rio de Janeiro, Departamento de Política Social, Programa de Pós-Graduação em Serviço Social, Rio de Janeiro, RJ, Brasil

${ }^{2}$ Universidade do Estado do Rio de Janeiro, Departamento de Política Social, Programa de Pós-Graduação em Serviço Social, Rio de Janeiro, RJ, Brasil

\begin{abstract}
A moderna construção da vigilância e do controle social no Brasil
Resumo: Este ensaio aborda a relação entre Estado e autoritarismo no Brasil, considerando as transformações dos mecanismos tradicionais e modernos de controle social, empregados pela classe dominante como força social e política na disputa pela direção moral e intelectual da sociedade brasileira. O objetivo é mostrar que a modernização da infraestrutura econômica implica no recrudescimento das formas de vigilância e controle social. Para isso, são apresentadas as mudanças no controle social a partir de 1930 até a Constituição Federal de 1988. Posteriormente, damos ênfase sobre as medidas neoliberais que deram ensejo às novas formas de controle no País. Por fim, conclui-se que a insuficiência das instituições de controle social, atualmente, tem em contrapartida a valorização da moral tradicional e o aumento da reivindicação social por segurança, formando dois pilares do autoritarismo neoliberal da política atual.
\end{abstract}

Palavras-chave: Estado. Autoritarismo. Controle social. Vigilância. Classe social.

The modern construction of surveillance and social control in Brazil

Abstract: This essay proposes to analyze the relationship between State and authoritarianism in Brazil, considering the transformations of traditional and modern mechanisms of social control, employed by the ruling class as a social and political force in the dispute for the moral and intellectual direction of Brazilian society. The objective is to reveal that the modernization of the economic infrastructure implies the intensification of the mechanisms of surveillance and social control. Thus, we present the changes in social control from 1930 until the Federal Constitution of 1988. Then, we emphasize the neoliberal measures that gave rise to new forms of control in the country. Finally, we conclude that the insufficiency of social control institutions currently has a counterpart in the valorization of traditional morality and the increase of the social demand for security, creating two pillars of the neoliberal authoritarianism of the current politics.

Keywords: State. Authoritarianism. Social control. Surveillance. Social class 


\section{Introdução}

O controle social na sociedade brasileira tem sido estudado a partir da chamada Era Vargas, momento em que parcelas da classe trabalhadora foram inseridas na máquina do Estado, mediante o acesso a um compósito de direitos sociais, concedidos de modo autoritário sob o controle do Ministério do Trabalho ${ }^{1}$. A relação entre a política social e o controle social do Estado concentrou a atenção nesse período, negligenciando o anterior no qual era notória a ausência de políticas sociais, mas não a de políticas de controle 2 . Portanto, tratar deste tema implica necessariamente considerar os mecanismos de sustentação da ordem política e social, que mudam historicamente em razão de fatores políticos, culturais, econômicos e sociais. Nesse sentido, o controle social extrapola o Estado, sendo (re)produzido culturalmente por meio de instituições que reproduzem valores, criam normas, conformam comportamentos e organizam rituais, expressando formas de sociabilidade constituídas em uma determinada ordem social. Assim, a coextensão entre a ordem das interações e a ordem social se realiza mediante o trabalho das instituições sociais.

Desde Durkheim, passando por Althusser, Foucault e Bourdieu, o controle social vem sendo estudado, com enfoque sobre as instituições sociais e a reprodução da ordem. De certa forma, as instituições asseguram a reprodução da ordem moderna, garantindo a sua regularidade. Acopladas às transformações que se desenvolvem nas relações de produção, as instituições se redefinem, a fim de inserir novos dispositivos e mecanismos para adaptação ou produção de novos padrões de comportamento. Isso não quer dizer que bastam as alterações nas normas institucionais para que as mudanças comportamentais sejam alcançadas. Contudo, é inegável a importância das instituições modernas na padronização de comportamentos definidos como ideais pela classe dominante.

Nesse sentido, o controle e a ordem social se reforçam, conferindo ao poder político a possibilidade de administração das crises. A resposta à questão social decorre dessa capacidade do Estado de exercer o poder político amenizando a violência da acumulação do capital por meio da incorporação das reivindicações da classe trabalhadora. Esse processo de expansão da cidadania (MARSHALL, 1967) vivenciado pelos países centrais contou com a formação de um Estado de Direito, estabelecido sob a burocratização do espaço público e a racionalização de diversas esferas, como a cultura, a economia e a política. No Brasil, tal processo tem sido interpretado como decorrente da modernização construída pelo autoritarismo político, que comandou a luta de classe com o objetivo do controle sobre a mudança. A compreensão da relação entre Estado, autoritarismo e classe social passa, portanto, pela consideração das formas de controle geralmente muito requisitadas nos momentos de recomposição da luta de classes em razão das transformações profundas na economia.

Na perspectiva aqui adotada, a vigilância e o controle social formam um par que compõe o conjunto das técnicas, procedimentos, instituições, representações sociais e ideologias que contraditoriamente servem como mediação na solução dos conflitos gerados na luta de classes. Constituem modalidades do exercício do poder que expressam a disputa e as formas de resistência à dominação. Não são exclusividades do Estado, mesmo porque reúnem os diversos elementos para a construção da hegemonia do capital. Contudo, são imprescindíveis ao Estado na sua função de assegurar a manutenção da ordem na sociedade capitalista.

O controle social é sempre exercido sobre a população ou grupo social de um determinado lugar, que pode ser uma empresa, um serviço, uma instituição pública ou privada. Pode ser mais ou menos coercitivo, conforme as regras que determinam os limites nos relacionamentos entre grupos distintos ou sujeitos com diferentes posições sociais. Difere-se da vigilância, que é basicamente informação, obtida por meio de estatísticas e da análise de dados nem sempre implicando em intervenção sobre a população.

Neste artigo, o foco está concentrado sobre os momentos em que o Estado brasileiro desenvolveu uma racionalidade compatível com a modernização da infraestrutura econômica, acentuando a vigilância e o controle sobre a classe trabalhadora. Primeiro, são apresentadas as mudanças relevantes no controle social a partir de 1930 até a Constituição de 1988. Em seguida, a ênfase está na disputa sobre os mecanismos de vigilância e de controle social democráticos, diante das medidas neoliberais que deram ensejo ao fortalecimento do neoconservadorismo no País.

A relevância deste estudo consiste em compreender a historicidade das formas de vigilância e de controle social, que evidenciam o autoritarismo político em diversos momentos, sobretudo aqueles de profundas transformações infraestruturais. Esta perspectiva destoa do caminho adotado pelos autores acima mencionados, expondo a singularidade do caso brasileiro. 


\section{O controle da questão social a partir de 1930: a industrialização e a construção de uma nova racionalidade política autoritária}

Com a Revolução - iniciada em 1930 e reforçada em 1937 -, inaugurou-se nova fase nas relações entre o Estado e a classe operária. A repressão do período anterior não se atenuou. Ao contrário, aprimorou-se através de organismos especializados no combate ao movimento sindical independente, ao Partido Comunista e à esquerda em geral. Porém, o que sucedeu de realmente novo foi que o Governo Vargas pôs em prática uma coerente e sistemática linha ideológica de conquista, controle e disciplinamento da classe trabalhadora. (FREIRE, 2020).

Nesse momento, viveu-se de forma mais nítida o processo de organização daquilo que veio a se tornar a estrutura de classes do Brasil industrial e capitalista. Isso implicava num esforço a fim de construir, pela invenção e pela descoberta, o ser brasileiro moderno. Dessa forma, a construção da modernidade do Brasil se transformou em projeto nacional, compreendido por uns como modelo, uma fonte de inspiração, e por outros como intérprete e criador do moderno a ser construído, associado à ideia de universalização, e não mais como réplica de um padrão que apenas certos círculos das elites entendiam ser conveniente para o País.

A mudança viria com a proposta de industrialização do Brasil. Novas instituições foram implementadas, na certeza de que a sociedade se modernizava e, por isso, necessitava de dispositivos e mecanismos capazes de alterar a institucionalidade do controle na produção social. A sociedade passaria por um processo de urbanização intenso, devendo ser organizada com base no funcionamento de instituições modernas que pudessem conter os conflitos de classe oriundos das contradições geradas com o avanço da industrialização. O desafio dos mecanismos de controle seria submeter os conflitos de classe à administração do Estado, construindo a conciliação entre os interesses antagônicos mediante a ideia de progresso e de desenvolvimento da nação. Doravante, o Estado assumiria a centralidade no controle da mudança.

Desse modo, as representações tradicionais que conformavam a ordem da burguesia agrária, no Brasil, ficavam sobrepostas à ideologia do Estado no âmbito da esfera pública. Nesse processo, a ampliação mesmo gradual dos direitos sociais representava a possibilidade dessa construção, fundada sob a formação de uma nova institucionalidade, construída sob uma sociedade homogeneizada na figura do mestiço, o elemento humano a partir do qual se combinava a ideia de democracia social com a ideologia da democracia racial de Gilberto Freire. Nessa engenharia política institucional, a ideologia política se sobrepunha às representações tradicionais da família e da Igreja, abrindo espaço para a construção de uma nova hegemonia, formada ainda por elementos arcaicos que dariam suporte à construção da modernidade, delineando os caminhos da modernização conservadora brasileira.

Esse seria o momento de romper com a ideia do descompasso entre o povo (formado por ex-escravos negros, indígenas, mestiços) e a República. Nesse intento, o Estado se incumbia da missão de dirigir os rumos da nação, tomando para o seu controle a sociedade paulatinamente submetida às instituições do poder administrativo. Significava que o Estado assumiria o controle da classe trabalhadora, ainda que concentrado sobre o espaço urbano. Tal movimento requeria situar o Estado no centro e acima da sociedade, controlando o ritmo do crescimento econômico, produzindo diferentes temporalidades do moderno e do atraso, expressas nas representações do espaço urbano e rural.

No final da década de 1920, sobrepor a racionalidade legal, base da cidadania, ao mandonismo local da ordem autoritária, hierárquica, organizada sobre o poder dos chefes locais, se apresentava como um problema para reprodução de uma ordem política representativa, democrática e descentralizada. Normativamente, a República parecia incompatível com a realidade social brasileira sustentada pelas oligarquias agrárias. $\mathrm{Na}$ época, a ordem pública não podia prescindir da atuação das grandes famílias no controle dos conflitos locais e na resolução de questões relacionadas à defesa do território nacional.

Nessas condições, a industrialização na Era Vargas representava o ingresso do Brasil no mundo moderno do século XXI. A ideologia do progresso combinada com a ideia de desenvolvimento nacional admitia o protagonismo do Estado na economia. Neste momento, há uma inflexão no controle social que se tornara efetivo, sendo exercido no âmbito dos mecanismos e dispositivos do Estado. No entanto, pela sua seletividade gradual, os direitos sociais foram constrangidos à administração, amparada nos aparatos repressivos sempre a postos.

Nessa conjuntura, o autoritarismo fora aprofundado e exercido, sobrepondo-se internamente às contradições do capitalismo que exacerbavam a crise política, acentuando a oposição entre as classes, chegando ao ápice 
com a propagação das ideologias autoritárias do nazismo e do fascismo, na década de 1930. A radicalização no Brasil guardava elementos da mentalidade fascista em razão de uma interpretação hegemônica da realidade brasileira, que suprimia a questão das desigualdades sociais e de sua relação com a estrutura das relações de comércio internacional, reduzindo a questão social a um problema de origem cultural, sendo este entendido como um obstáculo ao desenvolvimento da solidariedade cívica necessária à verdadeira ordem republicana.

Lançando, assim, a culpa sobre o povo, as bases ideológicas do autoritarismo serviam para justificar a intervenção do Estado, que inclusive encarava a miscigenação como uma estratégia para a solução dos nossos problemas de sociedade. Segundo Vianna (1986, p. 16), a nova sociedade, imatura e heterogênea, rejeitou "a ordem oligárquica e sua concepção de moderno, que não a compreendia", acreditando que a modernidade viria das "mãos das novas elites" que dariam forma, em 1930, ao novo Estado burguês (VIANNA, 1986, p. 16). Cabe ressaltar que, assim como os sindicatos, a partir de 1930, o moderno se estatiza. "A cidadania se amplia, o sistema da ordem se faz mais abrangente e universalizador. A condição, porém, desta cidadania ampliada estará na sua incompletude, restringida pela regulação exercida pelo Estado por meio de suas instituições corporativas" (VIANNA, 1986, p. 17).

O tipo de modernização que ocorre na sociedade brasileira - pelo alto, reguladora e disciplinadora da sociedade - embora acabe inibindo sua livre manifestação, é conduzida pelo Estado com a audácia de quem porta consigo a novidade - a indústria e a ideologia do industrialismo (VIANNA, 1986).

A compatibilidade com a ordem que se buscava criar se daria assim por uma engenharia institucional que mesclava o autoritarismo com o paternalismo da proteção social entendida como concessão à classe trabalhadora. No meio urbano, o controle não se exerceria predominantemente pela família e pela religião como era no rural, mas seria exercido pela polícia e pelo conjunto das instituições, criadas para assegurar as condições de reprodução de uma sociedade que se industrializava rapidamente. $\mathrm{O}$ tempo da industrialização e o da ampliação dos direitos sociais não era o mesmo, o que acentuava a impressão da necessidade da ordem para que o impacto das mudanças não escapasse ao controle do Estado. Com a carteira de trabalho instituída em 1932 e a participação nas representações classistas da Assembleia Nacional Constituinte em 1933, o poder decisório foi sendo deslocado do Legislativo para o Executivo, atrelando os benefícios sociais à condição de trabalhador (GOMES, 2005). De acordo com Vianna (1999),

No pré 35, entre o par mobilização/desmobilização, é a desmobilização que se reveste de caráter fundamental no trânsito para a estrutura corporativa. Para assumir a "representação" das classes subalternas, primeiro o Estado teria que liquidar suas organizações independentes, tendo reprimido seus líderes, cooptado outros e corrompido a uns tantos. A partir daí implementa-se a nova política, combinação de coerção e manipulação do consenso através da via corporativa, facilitada em parte pela mudança na composição da classe operária, com o recrutamento maciço de um contingente dócil `mobilização ideologizada praticada pelo Estado. (VIANNA, 1999, p. 178).

Desde então, a cidadania passaria a estar embutida nas profissões, vinculada ao lugar ocupado no processo produtivo, como reconhecido na lei, não sendo, portanto, resultante de um código de valores políticos, como observou Santos (1998) na sua concepção de cidadania regulada. O Estado criava um sistema previdenciário que permitia o controle do Ministério do Trabalho pelas oligarquias políticas e o controle dos organismos operários pela oligarquia sindical (SANTOS, 1998).

Não obstante, tal controle sobre a classe trabalhadora parecia não ser ainda suficiente. Entre 1935 e 1937, uma grande quantidade de sindicatos foi submetida à intervenção, o que transformou a questão social em uma questão de segurança nacional (GOMES, 1979). Diante da pressão e da resposta do Estado que procurava burocratizar as reivindicações, administrando o tempo ao reconhecimento de direitos para as categorias profissionais, a política social foi se expandindo no Estado Novo, com a consagração do salário mínimo (1938), a ratificação das férias anuais (1938), a Consolidação das Leis Trabalhistas (1943), e a institucionalização da Justiça do Trabalho (1941), no âmbito do Poder Executivo, encarregada da resolução de conflitos entre empregados e empregadores. O autoritarismo do Governo de Getúlio Vargas, após 1937, institui a unidade sindical (1939) de modo que apenas os sindicatos legalizados poderiam representar os interesses da categoria, recebendo dos trabalhadores a contribuição compulsória (1940). A greve e o lockout 
foram proibidos, considerados incompatíveis com os interesses da produção nacional ${ }^{3}$, em nome da qual a soberania do Estado seria exercida sobre toda a população (A ERA..., [201-?]).

A retomada da democracia se deu no breve espaço entre 1946 e 1964. Mesmo com a expansão das políticas sociais, a crise dos anos de 1960 retomou o autoritarismo à cena pública nacional. Nessa época, a modernização implementada no governo de Juscelino Kubitscheck não foi suficiente para superar o atraso da economia brasileira. A pressão por reformas estruturais se acentuava com o fortalecimento dos sindicatos e pela influência da ideologia que mobilizou a revolução nos países socialistas. O capital internacional se fazia presente na forma de empréstimos e implantação das multinacionais, que tornaram mais agudas as contradições na medida em que aprofundaram a dependência, ofuscada pela ideologia de desenvolvimento.

Conforme destacou Otavio Velho (2009, p. 114), o autoritarismo seja de forma centralizada ou descentralizada, explica melhor as ocorrências na vida política e social do que a oposição absoluta entre o poder privado e o Estado. Marilena Chauí (2014, p. 230) enfatiza o autoritarismo na história econômica do País, mostrando que a ascensão e o declínio dos ciclos econômicos corresponde à "subida e queda de poderes regionais, período em que o poderio regional é continuamente contrastado com o poder central, que ameaça as regiões para assegurar a suposta racionalidade e necessidade da centralização". Com isso, compreende-se por que os "partidos políticos são associações de famílias rivais ou clubs prives das oligarquias regionais" (CHAUÍ, 2014, p. 230). É possível considerar que daí surge a questão democrática, como concebida por Florestan Fernandes (1976) que entende a apropriação do público pelo privado não como a causa dos nossos problemas políticos e sociais, mas como consequência gerada pelo modo de acumulação na periferia dependente de maior extração mais-valia dos trabalhadores brasileiros para atender as exigências imperialistas do exterior. Assim se estabelece a base ao despotismo burguês acionado em momentos de crise.

Nos períodos mais graves da crise do capital, a classe dominante se associa aos conservadores, revigorando das bases do autoritarismo social, retomando ideologicamente os valores da família, da religião e da propriedade, no objetivo de construir na sociedade o consenso para a reconstrução do autoritarismo político. Resgata-se assim a moral tradicional e com ela os fundamentos da sua justiça, embasados na moral da vingança, base da ideologia da punição desmedida contra qualquer ato de desobediência. Daí a admissão da ordem militar sem demora. Ora, uma sociedade que se vê como o inverso das economias modernas, desde a raça, passando pela ausência de cultura cívica, chegando à incapacidade de acompanhar os avanços das forças produtivas, fortemente dependente do Estado, não precisa apenas de um governante, mas de um chefe de Estado, para ordenar a distribuição dos recursos, exercendo o poder como uma liderança situada acima das classes sociais.

Os anos da ditadura, inaugurada em 1964, reforçaram a impressão de que mais vale o comando do Estado do que a participação política dos cidadãos. Sob o domínio das forças armadas, o problema não era em si a existência ou não de um partido político de esquerda, mas, sobretudo, a forma como o exercício de controle sobre a classe trabalhadora seria conduzida. Daí a presença da esquerda como emblema da oposição ao regime. Sem desprezar a estratégia getulista de controlar a distribuição dos direitos sociais, a ditadura militar representou a expressão máxima do poder de vigilância sobre a classe trabalhadora. Não por acaso, o fim da ditadura implicou numa mudança dos mecanismos e dispositivos de controle social.

\section{A disputa pelo poder de vigilância e de controle social nos pós 1988}

Nos anos de 1980, a redemocratização da sociedade brasileira trouxe a necessidade da criação de novas modalidades de controle social para a ordem democrática que se pretendia gerar. Surgia a proposta da construção de uma ordem que baseada no consenso entre os diversos interesses mediante a participação no espaço público, que deveria não ser apenas representativa mais também direta. A Constituição Federal de 1988 admitiu a participação social em diversas instancias de poder, nos níveis federal, estadual e municipal. Alterou a função do Poder Judiciário, permitindo a sua atuação como seu intérprete, envolvendo-o em questões da administração do acesso à cidadania. Por conseguinte, o Poder Judiciário foi convocado a se fazer presente não apenas na sua função coercitiva e repressiva da punição, mas também como órgão atuante no processamento da conflitividade que envolve as expressões da questão social. Desse modo, o Estado passaria a responder às exigências do capital, sempre colocadas como um imperativo da ordem neoliberal, que avançava contrariando 
a Constituição Federal de 1988, transformando, sempre que possível, as expressões da questão social em processo judicial.

O Estado foi assim administrando o controle da institucionalidade sobre a classe trabalhadora, acelerando os ganhos de capital, destituindo os direitos sociais, enquanto emperrava o acesso às suas políticas, já que os direitos instituídos na CF 88 precisavam ser levados a um julgamento para serem alcançados. Assim, novos mecanismos foram sendo criados, obstaculizando o acesso universal aos direitos, comprometendo a seguridade social, ao passo que as classes dominantes conseguiam a garantia de seus lucros e rendimentos. Tal fato já colocava em xeque a democracia brasileira, que não conseguia resolver o déficit de cidadania e nem mesmo envolvia os mais pobres em instâncias de influência no poder, mas mantinha um aparato burocrático, repressivo, pesado no seu objetivo de gerenciamento da "questão social", seja para punir, seja para emperrar o acesso aos direitos.

Nesses termos, se a ditadura exerceu um controle ostensivo sobre a classe trabalhadora, mas procurou, contudo, ampliar a cobertura desses direitos; a democracia, desde a década de 1990, foi ampliando normativamente o acesso aos direitos, porém com base no processamento das demandas, na tentativa de manipular o tempo, postergando ao máximo a sua efetivação. Além disso, cabe lembrar que nem toda a população tem acesso ao Poder Judiciário e acaba desistindo antes mesmo de tentar. Com o modelo neoliberal implementado, as políticas sociais se tornaram escassas, incapazes de atender à demanda crescente de um contingente progressivo de ingressantes na informalidade em decorrência da precarização do trabalho e do aumento do desemprego, gerados com o avanço da reestruturação produtiva.

Desde a década de 1990, a vigilância sobre a classe trabalhadora tem se tornado mais incisiva e difusa. Além de poder contar com as inovações em termos do emprego da tecnologia (Cadastro Único da Assistência Social, Cadastro Desemprego, Cadastro do Setor Informal etc.), também se tornou mais ostensiva em razão da política de segurança, voltada substancialmente à repressão da polícia e até das forças armadas à população negra e jovem. Os mecanismos de controle da segurança pública, assim como o clamor crescente de políticas públicas repressivas e punitivas, demonstram a resposta historicamente determinada a certos grupos, acreditando que de alguma forma a ordem é colocada em risco, por causa das classes perigosas. Todo esse debate objetiva contribuir para o entendimento do grau de atrofiamento da cidadania em nosso país.

$\mathrm{Na}$ justificativa da segurança necessária à ordem urbana, as forças armadas se fazem urgentes no combate ao tráfico de drogas nas favelas. O propósito dessas ações tem como resposta muito pouco sobre o controle dessas atividades, mas expressam, sobretudo, o emprego da força armada contra o conjunto da classe trabalhadora, a população alvo das ações de vigilância e controle. Portanto, é a classe social determinante na concentração dos dispositivos de controle e de vigilância, que procuram assegurar a manutenção de uma ordem injusta, racista e autoritária contra os pobres. Não é à toa que jovens negros e pobres são os que mais sofrem com estas ações. Os negros, porque historicamente estigmatizados, formam o grupo sob suspeita mesmo quando ascendem socialmente. A classe trabalhadora, em grande parte sobrevivendo na informalidade, é identificada como pobre, carregando, assim, as representações sociais que a associam ao perigo. O resultado é o aumento do uso da força nos territórios estigmatizados, onde a população é mais desassistida e dependente das políticas sociais que mal conseguem acessar.

Não é surpresa então que assistamos, no caso das drogas, a passagem do modelo sanitário ao modelo bélico, para compor o que [Nilo] Batista denominou 'política criminal com derramamento de sangue'. O elemento bélico acompanhado do caráter religioso e moral da cruzada contra as drogas permite que esta política criminal não tenha limites, nem restrições, nem padrões regulativos. O modelo bélico traz marcas no judiciário, que ao tratar o suspeito ou condenado como inimigo, tolera violações de direitos e reifica os preconceitos contra as garantias constitucionais (BATISTA, 2011, grifo do autor).

Desse modo, o controle sobre a classe trabalhadora vai se tornando bélico em substituição as outras formas de controle. A intenção da massificação ou da universalização da política vai sendo abandonada. $\mathrm{O}$ domínio sobre a classe trabalhadora empobrecida acentua o estigma, em decorrência da desigualdade estrutural. Recai sobre os mais pobres, a culpa do atraso e dos problemas para as oportunidades de desenvolvimento em um país com baixa instrução, sem saneamento, sem capital social. Conforme destacou Chauí, a naturalização da desigualdade social no Brasil é uma violência que não é percebida como tal, fazendo com que se torne 
normal a polarização "entre a carência absoluta das camadas populares e o privilégio absoluto das camadas dominantes e dirigentes". (CHAUÍ, 2014, p. 230).

$\mathrm{Na}$ democracia das três últimas décadas, as mudanças no controle social instituídas no sentido da democratização do poder e da redução da desigualdade social têm falhado, se consideramos o problema da centralização e da concentração do capital. A supremacia do capital financeiro impulsionada com a mundialização da economia tem requerido mudanças na relação entre produção e reprodução social. Atualmente, as lutas têm sido pela resistência contra a destituição de direitos e o aumento da repressão do Estado sobre a classe trabalhadora. Por sua vez, a ausência de proteção social situa a questão do controle social e da vigilância como um problema para o Estado, na medida em que se faz necessário assegurar as condições para a acumulação financeira, gerando inúmeras formas de expropriação, ao mesmo tempo em que permite aos fluxos de capitais entrada e saída do país sem qualquer controle. Nesse sentido, quanto mais livre for a circulação de capitais, mais violenta será a ação das forças repressivas contra a classe trabalhadora.

Nesses termos, o Estado se torna imprescindível na viabilidade da mundialização financeira. Contudo, se a economia se internacionaliza, os conflitos de classe, não. No contexto do avanço do neoliberalismo, a vigilância e o controle, na sua base jurídica, vão se tornando rarefeitos com relação à seguridade social, mas rígidos em termos das forças de segurança. Há nesse processo uma mudança com relação aos dispositivos e mecanismos de controle que vão se tornando menos democráticos, sendo preteridos aos aparatos repressivos considerados imprescindíveis à proteção da sociedade. A vigilância e o controle social vão assim se tornando centrais, reforçando na sociedade seus apelos quanto à articulação entre a ordem e as forças de segurança, mais do que o respeito à sua base no direito.

Objetiva e subjetivamente, o controle social não deixou de ser exercido nas instituições de educação, saúde e assistência social, porém a ênfase tem sido dada aos aparelhos pelos quais a moral conservadora sai fortalecida, tais como a família, a religião, a polícia e o exército. A interpretação da crise como um problema moral se fortalece, reduzindo a possibilidade de ser enfrentada com uma racionalidade capaz de fazer com que os interesses possam ser disputados politicamente e convertidos em direitos. O autoritarismo assim é revigorado. A CF 88 é colocada em questão, como se não fosse capaz servir de base à construção de uma ordem conformadora do Estado Democrático de Direito, retomando a crítica já conhecida no passado de comportar um direito não baseado em dados da experiência, um idealismo utópico ${ }^{4}$.

Esta mentalidade respalda o autoritarismo à medida que suspende a possibilidade de compatibilizar democracia com o controle social. O que está em questão não é apenas o grau de exploração da força de trabalho, que tem se intensificado com o aumento da jornada e a precarização dos direitos, mas é também a possibilidade da classe trabalhadora se organizar com a finalidade de exercer pressão sobre os governos, ou seja, de participar na formulação das normas referentes aos limites para o exercício do controle social. Diante disso, constata-se a existência de mais uma crise na sociedade brasileira, que se deu antes mesmo de completar a democratização das suas instituições. De certa forma, as esquerdas negligenciaram o crescimento político e social das forças mais conservadoras, que na primeira oportunidade tomaram o poder.

Neste sentido, a crise revela a incapacidade dos dispositivos e mecanismos de controle social da racionalidade moderna de conferir um sentido de cidadania. Diante da crise que exige um quinhão cada vez maior do orçamento público para garantir os rendimentos dos investidores nacionais e internacionais, os ideais da república parecem inalcançáveis mesmo na democracia. A crise brasileira afeta o funcionamento das escolas, das instituições de assistência social, dos hospitais, enfim, das políticas sociais que vão sendo sucateadas.

O conservadorismo sempre fez parte da cultura política brasileira e sempre persistiu em nossa realidade, e não pode ser compreendido isoladamente. Ele é uma expressão da luta de classes, isto é, manifesta em sua aparência a dinâmica de luta entre interesses antagônicos que formam a sociabilidade burguesa (FREIRE, 2018).

Como observou Barroco (2011), é nesse contexto que o conservadorismo tem encontrado espaço para se expressar, se ancorando em mitos, motivando expressões autoritárias, preconceituosas e irracionalistas, atitudes preconceituosas, moralizantes, intolerantes e reacionárias. Uma das expressões dessa ideologia é a reprodução do ódio e do medo social, para que se naturalize a barbárie e se clame por ampliações e formas de controle e intervenções militarizadas.

O neoliberalismo, ao naturalizar as desigualdades, concentra sobre as famílias a responsabilidade do investimento em educação, saúde, assistência social, a fim de que arque todas as suas despesas com o bem-estar. Assim sendo, se revitaliza na sociedade brasileira os traços marcantes da sua cultura fincada na 
solidariedade familiar e na moral religiosa. O neoliberalismo, portanto, dá relevo aos elementos básicos do neoconservadorismo político que se apoderou do Estado.

Isso revela que o neoconservadorismo não é resultado do golpe de 2016, que deixou em evidência a presença da moral evangélica e do discurso de valorização da família, contra a corrupção na política, como o principal problema nacional. O que houve foi o desdobramento ideológico da política neoliberal, que já era concentrada na família, reforçando a moral social conservadora no Brasil. Nesse sentido, o neoliberalismo рагіи о neoconservadorismo brasileiro, germinando o solo por onde caminha o bolsonarismo.

\section{Considerações Finais}

O controle social e a vigilância através de seus suportes marcam sua presença em vários momentos políticos da história brasileira expressando o autoritarismo, nas formações concretas e nas inconscientes, com raio de ação muito maior e desconhecido do que imaginamos à primeira vista. Contudo, o que as mudanças nas modalidades de controle e vigilância revelam é sua intrínseca relação com as transformações infraestruturais econômicas e com as ideologias políticas, que se reformulam a fim de assegurar o domínio do Estado sobre os processos de mudança.

Tal processo ocorre mediante a subordinação da classe trabalhadora, fortemente reprimida em razão das condições do capitalismo dependente e periférico que exige uma parcela maior da extração da mais valia, reproduzindo o aumento progressivo das desigualdades sociais. As expectativas de mudança geradas com as inovações democráticas no controle social, não alcançaram o resultado esperado em decorrência do avanço da política neoliberal, que provocou a redução progressiva das políticas sociais e dos direitos trabalhistas.

$\mathrm{O}$ acirramento da luta de classes em decorrência do desemprego estrutural, da precarização do trabalho e do crescimento da violência, fez a sociedade reclamar por segurança do Estado, seguindo a lógica da política de segurança que culpabiliza a vítima e não os principais responsáveis pelo caos social. Com isso, os pobres voltaram a ser identificados como "classes perigosas", tornando-se o alvo das ações de vigilância e de controle do Estado.

Em termos ideológicos, o neoliberalismo deu ensejo ao neoconservadorismo, que para suprir o déficit do controle das instituições modernas, retomou a moral tradicional e cobrou ao mesmo tempo o aumento da repressão do Estado contra os mais pobres. Sendo assim, o neoconservadorismo representa mais do que uma ideologia, pois se constitui no desdobramento do neoliberalismo, convertendo-se numa estratégia de governo. Trata-se então de uma ideologia e ao mesmo tempo de uma estratégia de vigilância e controle contra a classe trabalhadora, elaborada com a finalidade de atender os interesses da acumulação financeira, que se revelam incompatíveis com os mecanismos de vigilância e controle democráticos, definidos a partir da CF 88 .

\section{Referências}

BARROCO. M. L. S. Barbárie e neoconservadorismo: os desafios do projeto ético-político. Revista Serviço Social e Sociedade, São Paulo, n. 106, p. 205-218, abr./jun. 2011.

BATISTA, V. M. Autoritarismo e controle social no Brasil. Revista Sem Terra, Rio de Janeiro, n. 10, 2011. Não paginado. Disponível em: https://www.lainsignia.org/2001/marzo/cul_040.htm. Acesso em: 20 junho 2020.

CHAUÍ, M. Manifestações ideológicas do autoritarismo brasileiro. São Paulo: Editora Fundação Perseu Abramo, 2014.

FERNANDES, F. A Revolução Burguesa no Brasil: Ensaio de interpretação sociológica. Rio de Janeiro: Zahas, 1976.

FREIRE, S. de M. A instrumentalidade dos conservadorismos no atual contexto de hegemonia do capital. Quadranti: Rivista Internazionale di Fi losofia Contemporanea, Salerno, v. 6, n. 2, p.174-195, 2018.

FREIRE, Silene de Moraes. Cultura Política e Revolução Burguesa no Brasil: a instrumentalidade do Pensamento autoritário, Rio de Janeiro, Gramma, 2020.

FUNDAÇÃO GETÚlIO VARGAS (FGV) Centro de Pesquisa e Documentação de História Contemporânea do Brasil, São Paulo. A Era Vargas: dos anos 20 a 1945. [201-?]. Disponível em: https://cpdoc.fgv.br/producao/dossies/AEraVargas1/anos37-45/ DireitosSociaisTrabalhistas. Acesso em: 22 jun. 2020.

GOMES, A. de C. A Invenção do Trabalhismo. Rio de Janeiro: FGV, 2005.

GOMES, A. de C. Burguesia e Trabalho: Política Social e Legislação Social no Brasil (1917-1937). Rio de Janeiro: Campus, 1979. 
MARSHALL, T. H. (1949). Cidadania, classe social e status. Rio de Janeiro, Zahar 1967.

SANTOS, W. G. dos. Décadas de espanto e uma apologia democrática. Rio de Janeiro: Rocco, 1998.

VELHO, O. G. Capitalismo autoritário e campesinato um estudo comparativo a partir da fronteira em movimento. Rio de Janeiro: Centro Edelstein de Pesquisas Sociais, 2009.

VIANNA, L. W. A judicialização da política e das relações sociais no Brasil. Rio de Janeiro, Revan, 1999.

VIANNA, L. W. Travessia: da abertura à Constituinte 86. Rio de Janeiro: Taurus, 1986.

VIANNA, O. O idealismo da Constituição. São Paulo: Companhia Editora Nacional, 1939.

\section{Notas}

1 Apesar do intervencionismo estatal e das leis trabalhistas terem sido intensificados na década de 1930, a peculiaridade da natureza do Estado nesse período não reside nesses elementos, mas, sim, na sua inclusão em uma ordem corporativa.

2 A ênfase no recorte temporal a partir de 1930 não significa que antes a vigilância e o controle social não existiam ou não eram relevantes. Pelo contrário, o período anterior à década de 1930 foi profícuo em termos das determinações que demonstram a sua centralidade, sobretudo, dada à ênfase sobre a família e a Igreja, duas instituições que funcionam como suportes ao controle do Estado na sociedade brasileira até os dias de hoje. Devido às limitações quanto ao aprofundamento do controle social, família e religião neste artigo, a opção dos autores foi enfatizar o período em que o capitalismo brasileiro incorporou a racionalidade inerente à modernidade.

3 Consultar: A Era Vargas dos anos 20 a 1945. (FUNDAÇÃO GETÚLIO VARGAS, [201-?]).

4 A expressão idealismo utópico pertence a Oliveira Vianna e foi empregada na sua crítica à Constituição federal de 1991, sendo definido como "todo e qualquer conjunto de aspirações políticas em íntimo desacordo com as condições reais e orgânicas da sociedade que pretende reger e dirigir”. (VIANNA, 1939, p. 10).

\section{Vânia Morales Sierra}

vaniasierra@yahoo.com.br

Doutora em Sociologia, IUPERJ/Université Paris-Nanterre

Professora associada da Faculdade de Serviço Social da Universidade do Estado do Rio de Janeiro (UERJ)

\section{Silene de Moraes Freire}

silenefreire@gmail.com

Doutora em Sociologia pela Faculdade de Filosofia e Ciências Humanas da Universidade de São Paulo (USP)

Professora Titular da Faculdade de Serviço Social da Universidade do Estado do Rio de Janeiro (UERJ)

\section{UERJ}

Rua São Francisco Xavier, 524 - Maracanã

Rio de Janeiro - Rio de Janeiro - Brasil

CEP: 20550-900

\section{Agradecimentos}

Não se aplica.

Agência financiadora

Não se aplica.

Contribuições das autoras

As duas autoras contribuíram igualmente para a organização das ideias e escrita final.

\author{
Aprovação por Comitê de Ética e consentimento para \\ participação \\ Não se aplica. \\ Consentimento para publicação \\ Consentimento das autoras. \\ Conflito de interesses \\ Não há conflito de interesses.
}

